\title{
TRAJETÓRIA DO CURSO DE LICENCIATURA EM EDUCAÇÃO DO CAMPO NA UNIVERSIDADE ESTADUAL DE ALAGOAS: POSSIBILIDADES E DESAFIOS
}

\author{
LICENSING COURSE TRAJECTORY IN RURAL EDUCATION AT THE ALAGOAS \\ STATE UNIVERSITY: POSSIBILITIES AND CHALLENGES
}

\begin{abstract}
Sanadia Gama dos Santos ${ }^{1}$
Resumo: Este artigo faz uma descrição sobre a proposta de oferta do curso de Licenciatura em Educação do Campo da Universidade Estadual de Alagoas, bem como seus desafios e resistência para se manter enquanto proposta de Educação Superior em um estado historicamente marcado pelas influências da colonização europeia e das oligarquias dominantes. Como aporte teórico trazemos reflexões de Freire (2009), Caldart (2004 e 2012) e Arroyo (2007). A metodologia é qualitativa, do tipo intepretativista e as informações descritas estão presentes no Projeto Político do Curso (2009), como também no Parecer CEE 040/2014 que regulamenta a oferta de Educação do Campo no Sistema Estadual de Educação de Alagoas. É importante ressaltar que a criação de uma Licenciatura em Educação do Campo surge não somente como uma necessidade estratégica educacional e econômica, mas também como um projeto contra-hegemônico do agronegócio e latifúndio historicamente marcado nas bases agrícolas do Estado.
\end{abstract}

Palavras-chave: Licenciatura em Educação do Campo; formação docente; Educação do Campo.

\begin{abstract}
This paper describes the proposal to offer the Undergraduate Course in Rural Education at the State University of Alagoas, as well as its challenges and resistance to remain as a proposal for Higher Education in a state historically marked by the influences of European colonization and the dominant oligarchies. As a theoretical contribution we bring reflections by Freire (2009), Caldart (2004 and 2012) and Arroyo (2007). The methodology is qualitative, of the interpretive type and the information described is present in the Political Project of the Course (2009), as well as in Opinion CEE 040/2014 that regulates the offer of Rural Education in the State Education System of Alagoas. It is important to note that the creation of a Degree in Rural Education emerges not only as a strategic educational and economic need, but also as a counter-hegemonic project of agribusiness and latifundium historically marked in the agricultural bases of the State.
\end{abstract}

Keywords: Undergraduate Course in Rural Education. Teacher Education; Rural Education.

\section{Introdução}

Este artigo tem como objetivo descrever a proposta do curso de Licenciatura em Educação do Campo, da Universidade Estadual de Alagoas (UNEAL), seus desafios e sua resistência para se manter como uma proposta de Educação Superior em um estado marcado pela oligarquia e por uma história de colonização e de dominação europeia, fortemente pela exploração da cana de açúcar e dos engenhos no litoral.

A Licenciatura em Educação do Campo surge em um cenário historicamente marcado pelo latifúndio, exploração da cana de açúcar e pela constituição étnica da presença do negro e do indígena colonizados pelo branco europeu. O curso é resultante de um convênio da UNEAL com o Ministério da Educação/Secretaria de Educação Continuada, Alfabetização, Diversidade e Inclusão

\footnotetext{
${ }^{1}$ Universidade Estadual de Alagoas, Arapiraca, AL, Brasil.
} 
- MEC/SECADI (Resolução nº 02/2013 CONSU/UNEAL), mantido pela Universidade Estadual de Alagoas, na modalidade presencial com período de duração de quatro anos.

Nesse sentido, vale frisar que a Educação no estado de Alagoas, sobretudo as Universidades, em especial a Universidade Estadual de Alagoas, foi criada com cursos de licenciatura para contribuir com a formação de novos professores no interior do estado.

Vale ressaltar que a Licenciatura em Educação do Campo da UNEAL foi implantada em 2011 e sua conclusão foi em 2017. Foram inúmeros desafios para a sua manutenção e permanência até o seu encerramento. Sua efetivação após empenho e luta do professor responsável e gestores da Universidade. Infelizmente, não houve nova turma por falta de financiamento público via UNEAL, todavia o interesse da gestão da Universidade era tamanha em prosseguir com mais turmas, afim de atender a outras regiões em termos de formação superior específica para educadores e educadoras que atuam em escolas do campo no Estado de Alagoas, como também em movimentos sociais e sindicais do campo alagoano.

\section{O programa Licenciatura em Educação do Campo da UNEAL}

A criação de uma Licenciatura em Educação do Campo (PROCAMPO/UNEAL) surge não somente como uma necessidade estratégica educacional e econômica, mas também como um projeto contra-hegemônico que vai na contramão das políticas agrícolas desenvolvidas nos últimos dez anos em Alagoas. Além disso, entre as ações que colaboram com o trabalhador do campo na região, uma que se destaca é a formação e atuação do FEPEC (Fórum Estadual Permanente de Educação do Campo (FEPEC), bem como as atividades da RECASA (Rede de Educação Contextualizada do Agreste e Semiárido), que têm servido de suporte e espaço de discussão para educadores e trabalhadores campesinos.

Visando atender às demandas existentes nas escolas da rede pública de educação, em 2002, a UNEAL criou o Programa Especial para Graduação de Professores da UNEAL (PGP), com a meta de contribuir com a qualificação de professores da rede pública estadual e municipal, visto que a maioria não possuía cursos de licenciatura em áreas específicas, e assim reduzir a carência de professores em disciplinas. Foram propostos na época quatro licenciaturas: Pedagogia, Letras-português, Matemática e Ciências Biológicas, em oito polos: Arapiraca, Santana do Ipanema, Palmeira dos Índios, São Miguel dos Campos, União dos Palmares, Matriz do Camaragibe, Delmiro Gouveia e Viçosa.

Ao expandir cursos para áreas não voltadas para a formação de professores, enquanto Universidade, como os cursos de Zootecnia, Ciências Contábeis, Administração de empresas, Administração Pública e Direito, o fez com base na demanda existente no Estado de Alagoas, notadamente, no agreste e sertão.

Entretanto, careceu na época de atividades educacionais específicas; atividades estas voltadas para atender a demanda existente de agentes sociais que desenvolvam ações específicas nas escolas do campo, por exemplo. Nesse sentido, vale frisar que a Educação no Campo, no Brasil, é abordada por diversos autores, como Calazans (1993), Leite (1999), Peludo (2001), Caldart (2004) e Arroio (2007), dentre outros, como relegada, de certa forma, ao abandono pelo poder público.

Esses autores são unânimes em retratar a Educação no Campo, em diversos períodos históricos, como sendo aquela pensada sob o paradigma urbano, para a lógica urbana. Ou seja, não teria ocorrido, até finais do século XX, propostas organizacionais de educação que percebesse as peculiaridades dos homens e das mulheres do campo. 
Uma hipótese com frequência é que nosso sistema escolar é urbano, apenas pensado no paradigma urbano. A formulação de políticas educativas e públicas, em geral, pensa na cidade e nos cidadãos urbanos como protótipo de sujeitos de direitos. Há uma idealização da cidade como espaço civilizatório por excelência, de convívio, de sociabilidade e socialização, da expressão da dinâmica política, cultural e educativa (ARROYO, 2007, p. 2).

Arroyo assevera que o campo é visto como lugar do atraso, ou seja, as condições pensadas para o campo não são reconhecidas ou legitimadas, principalmente nas instituições de ensino, pois não há políticas articuladas e nem pensadas para esse lugar. O ensino ainda é calcado sob a égide urbana, assim como o currículo e o ato de ensinar. De igual modo, o letramento se confunde com a alfabetização no sentido de focalizar o ensino como mera decodificação de palavras, para dar resultados quantitativos aos órgãos financiadores que regem a educação.

Assim, os educadores e educadoras da escola do campo também possuem a formação pautada no paradigma urbano, por falta de políticas de formação e qualificação específica para a educação do campo.

\section{Formação de Educadores e Educadoras do Campo: avanços e desafios}

Refletir sobre Educação do Campo transcende a lógica do modelo escolar, pois este é um movimento de reivindicação que garanta a implementação de princípios políticos e ideológicos culturalmente instaurados na concepção de educação específica para os povos do campo, justamente para fortalecermos a lógica de que há uma especificidade nas modalidades educacionais e que esse modelo torne-se autoprodutivo, com base em uma proposta de reforma agrária, agroecológica e que se contraponha ao modelo do agronegócio.

Como estratégia de desenvolvimento do curso de licenciatura em Educação do Campo, este foi dividido em duas grandes áreas: Ciências da Natureza e Matemática e Línguas, Artes e Literatura.

Nesse sentido, vale ressaltar que, embora o PROCAMPO seja um programa, Alagoas possui um cenário de tensões e de resistência pautados pelos movimentos campesinos de Alagoas, a exemplo do Movimento dos Trabalhadores Rurais Sem Terra (MST), e o Fórum Estadual de Educação do Campo composto por diversos movimentos, fruto dessas ações coletivas, foi construído o parecer CEE 040/2014 que regulamenta as políticas de Educação do Campo no estado e garante o monitoramento e a efetivação das políticas de Educação do Campo, o que respalda na formação dos Educadores na licenciatura em Educação do Campo o pleno cumprimento das ações propostas de intervenção em suas comunidades e respectivos locais de atuação desses educadores envolvidos no processo de formação.

Historicamente, Alagoas vem mantendo os maiores índices de analfabetismo no país, conforme números de censo, incluindo tanto os trabalhadores do campo quanto da cidade. Socialmente, é apontado que o acesso à educação favorece tanto a ascensão social como a reprodução das desigualdades sociais. Nessa lógica de nacionalismo, a ideia de acesso à escola como fator essencial para minimizar desigualdades passa a ser um paradoxo ou um mito do letramento (SIGNORINI, 1994).

Nesse sentido, o professor, possui, além das prerrogativas profissionais, a incumbência de favorecer as aspirações sociais de acesso ao conhecimento e, com esse, a possível progressão social de seus estudantes. Entretanto,

No caso específico da área rural, além da baixa qualificação e salários inferiores aos da zona urbana, eles (professores) enfrentam, entre outras, as 
questões de sobrecarga de trabalho, alta rotatividade e dificuldades de acesso à escola, em função das condições das estradas e da falta de ajuda de custo para locomoção (BRASIL, 2003, p. 23).

Nesse sentido, a educação passa a ser vista como produto do mercado, pois a maioria dos professores, sobretudo em Alagoas, por não terem remuneração suficiente para sobreviverem, precisam trabalhar em outros lugares para complementar a renda. Dados mostram que professor de $1^{\circ}$ ao $5^{\circ}$ ano teve sua carga-horária aumentada para 25 (vinte e cinco horas-aula) sem, necessariamente, ter um salário correspondente. O que estamos demonstrando é que, com 20 (vinte) ou 25 (vinte e cinco) horas, não há possibilidade nem de manutenção econômica do professor nem de dedicação ao ensino.

Quanto à escolaridade dos professores, temos os seguintes dados:

No ensino fundamental de $1^{\mathrm{a}}$ a $4^{\mathrm{a}}$ série, apenas $9 \%$ apresenta formação superior, enquanto na zona urbana esse contingente representa $38 \%$ dos docentes. $\mathrm{O}$ percentual de docentes com formação inferior ao ensino médio corresponde a $8,3 \%$ na zona rural, indicando a existência de 18.035 professores sem habilitação mínima para o desempenho de suas atividades. (BRASIL, 2003 p. 23)

Em Alagoas, estado que possui maiores índices de analfabetismo, essa situação parece ser ainda mais agravada pela dificuldade de formação de seus educadores. Nesse sentido, não haveria, propriamente, uma política educacional voltada para os saberes dos atores e atrizes do campo, mas uma acomodação, adaptação ou mesmo uma continuidade das escolas urbanas. As educadoras e os educadores do campo, na verdade, seriam os mesmos, formados por paradigmas urbanos que, em maior ou menor medida, deveriam adaptar as atividades pedagógicas à realidade do campo, mesmo que, durante sua formação, não tenham tido aprofundamentos nas áreas de atuação.

Diante desses dados informados, a Universidade Estadual de Alagoas, atuante na maioria dos municípios alagoanos desde 2000, sentiu a necessidade de uma demanda específica para a criação de um curso de Licenciatura em Educação do Campo em Alagoas. Naquele cenário, a UNEAL possuía apenas um curso voltado para a formação agrária, o de Zootécnica, no Campus III, em Santana do Ipanema, no sertão alagoano. Ou seja, os cursos de licenciatura existentes visavam à formação de educadoras e educadores, geralmente centrados no homem e na mulher urbanos.

Nesse sentido, a criação de um curso de licenciatura em Educação do Campo constituiu uma aproximação entre os movimentos sociais do campo e a universidade, redimensionando pesquisa e extensão para demandas do campo, contribuindo no redirecionamento da vida social do homem e da mulher do campo.

Vale lembrar que, na época em que o curso foi criado, o cenário político nacional também era favorável para essa criação. A criação da SECAD/MEC, depois SECADI facilitou apoio maior em termos de estruturação e financiamento do curso, como também no sentido de despertar no poder público estadual a continuação, reconhecimento e manutenção de um curso regular na instituição. Segundo o Projeto Político Pedagógico do PROCAMPO (2009), os resultados esperados com a criação da Licenciatura em Educação do Campo são:

Para o ensino, para os educandos e educadores envolvidos:

- Ampliar o conhecimento do aluno, possibilitando os saberes entre Universidade e realidade local.

- Possibilitar a utilização de novos conhecimentos no cotidiano dos alunos.

- Disseminar conhecimentos adquiridos no âmbito das comunidades assistidas. 
- Fortalecer ações conjuntas de reflexão individual e da prática pedagógica.

Do impacto das ações do projeto na comunidade acadêmica e sociedade:

- Favorecer a ampliação do acesso à Universidade de agrupamentos sociais tradicionalmente excluídos.

- Fortalecer mecanismos de interação Universidade-Escola Básica.

- Favorecer intercâmbio com instituições nacionais e internacionais, capacitação de pesquisadores, criação de grupos de pesquisa e divulgação do conhecimento produzido.

- Maior difusão do conhecimento científico produzido em âmbito local, nacional e internacional.

- Consolidar a extensão universitária, como prática institucional de validade comprovada, efetivada pelo intercâmbio entre universidade/comunidade.

- Valorizar conhecimentos tradicionais no processo de produção cientifica.

Quanto aos objetivos, o curso de Licenciatura em Educação do Campo se propôs a formar e habilitar professores da Licenciatura Plena em Educação do Campo, para atuarem nos anos finais do Ensino fundamental e Ensino médio, com áreas de concentração em Línguas, Artes e Literatura e Ciências da Vida, da Natureza e da Matemática.

O perfil do curso foi multidisciplinar, pois nesse sentido, o conceito de Educação transcende o senso comum. Nesse sentido, o Curso de Licenciatura em Educação do Campo atua no exercício da docência nos anos finais do ensino fundamental, no ensino médio e superior, nas disciplinas decorrentes de sua formação geral e, nas habilitações específicas de linguagens (expressão oral e escrita em Língua Portuguesa, Artes e Literatura) e Ciências da Vida, da Natureza e Matemática. Possui validade para os professores em exercício nas escolas do campo, além de outros professores e profissionais que atuam em programas governamentais; jovens e adultos que desenvolvem atividades não-escolares nas comunidades do campo; associações comunitárias rurais; sindicatos do campo; organizações camponesas em geral e; interessados em conhecer o mundo rural, com seus dilemas e perspectivas.

A proposta do curso de Licenciatura em Educação do Campo pretende definir profissionais comprometidos com o domínio e conhecimento do processo educativo. Nesse sentido, seu processo educativo é dialógico, pois a formação acontece em todos os espaços da vida social e humana, considerando que, conforme Antunes-Rocha (2011, p. 41), "as necessidades presentes na escola do campo exigem um profissional com uma formação mais ampliada, mais totalizante, já que ele tem que dar conta de uma série de dimensões educativas presentes nessa realidade".

Outro perfil do egresso do curso é que articule teoria, pesquisa e prática social em comunidades rurais, que tenha capacidade para realizar um trabalho multidisciplinar, tenha responsabilidade social, ética e abertura para as diferenças, saiba atuar tanto nos espaços da escola quanto em outros espaços educativos.

Na configuração da matriz curricular e do Projeto Político Pedagógico do PROCAMPO, essas prerrogativas devem ser aperfeiçoadas e constituídas durante a formação em regime de alternância: Tempo-Universidade (TU) e Tempo-Comunidade (TC), interrelacionado com o que foi produzido e desenvolvido nas aulas teórico-práticas.

Pelo fato do PROCAMPO ser um programa, há muitos questionamentos dos movimentos sociais sobre o reconhecimento e a implementação financeira dos governos, sobretudo do governo federal em garantir formação continuada e regular como política pública para as populações do campo. 
As aulas aconteciam em dias de sexta-feira e de sábado, com uma atividade mensal do TC e outra em sala de aula para refletir os conteúdos específicos do curso, inter-relacionados com a realidade do campo, história do campesinato alagoano e no Brasil, dentre outras. A matriz curricular, conforme apresentado abaixo, foi definida da seguinte maneira:

Disciplinas do núcleo de formação:

\begin{tabular}{|l|l|}
\hline \multirow{5}{*}{ ESTÁGIOS E ATIVIDADES } & \multicolumn{1}{|c|}{ DISCIPLINAS } \\
\cline { 2 - 2 } & Seminários Integradores I \\
& Seminários Integradores II \\
& Seminários Integradores III \\
& Seminários Integradores IV \\
& Seminários Integradores V \\
& Seminários Integradores VI \\
& Estágio Curricular Supervisionado1 \\
& Estágio Supervisionado II \\
& Estágio Supervisionado III \\
& Trabalho de Conclusão de Curso I \\
& Trabalho de Conclusão de Curso II \\
\hline EIXO COMUM & Introdução à Sociologia, Introdução à \\
& Filosofia, Antropologia, Ciência Política, \\
Geografia Rural, Educação do Campo I - & Políticas Públicas do Campo e para a \\
& Educação, Sociologia da Educação, \\
& Movimentos Sociais e Cidadania, Psicologia \\
da Educação, Crédito Rural e Políticas \\
Agrícolas, Agricultura I, Educação do \\
Campo II, Gestão da Unidade de Produção, \\
Educação Brasileira: Legislação e Políticas \\
Públicas, Dinâmicas Sociais e Recomposição \\
do Espaço Rural, Formação Econômica, \\
Social e Política de Alagoas, Didática Geral, \\
Projetos de Pesquisa e Intervenção Social I, \\
Agricultura II, Elementos da Geologia, \\
Língua Portuguesa I, Matemática Básica, \\
Projetos de Pesquisa e Intervenção Social II, \\
Metodologia do Ensino de Ciências \\
Humanas e Sociais, Análise do Discurso, \\
Literatura Brasileira I.
\end{tabular}

Tabela 1: Matriz curricular comum dos cursos. Fonte: PPP/PROCAMPO, 2009.

Nesse sentido, um curso de licenciatura para o campo na UNEAL possui uma dimensão relacional e dialógica. Seus avanços permitem um olhar amplo para além do currículo, porque requer uma transformação cultural na consciência dos sujeitos envolvidos, tornando um indivíduo político e engajado em suas realidades locais e com as necessidades reais da Educação do Campo.

Embora muitos documentos tenham sido constituídos dos frutos de lutas e reflexões para garantir a sua efetividade, sabemos que a base da sociedade é vertical e hegemônica sobre o 
pensamento conservador, que evidencia os centros urbanos e ameaça a permanência e fortalecimento de políticas do campo, que garantam sustentabilidade e sucessão rural.

\section{Considerações finais}

As práticas de ensino em Educação do Campo propõem um olhar inclusivo, mais sensível e aberto a questões fundamentais: a princípio atender a demanda de formação dos estudantes de cursos de licenciatura para uma modalidade de Educação que tem caráter dinâmico, político e crítico, fazendo enxergar realidades locais que demandam um currículo contextualizado da realidade, faz mirar o olhar para outras dimensões da educação e nos faz refletir a multiplicidade que a prática de ensino nos exige e revela.

Sendo assim, os objetivos propostos para a formação de professores em um curso de licenciatura, apresentando a importância que cada uma tem na formação de novos professores.

Todo o transcorrer do curso possui em sua natureza um viés interdisciplinar, político e e requer um profundo diálogo fora da Universidade com os movimentos do campo no Estado, em uma dimensão relacional e dialógica, capaz de romper os muros da Universidade e abrir espaços de diálogo e de construção articulada às propostas e necessidades locais para inserção na formação e na prática de ensino dos futuros professores.

Vale ressaltar que numa realidade marcada por dificuldades educacionais como a de Alagoas, trazer a Educação do Campo como parte da formação dos futuros profissionais da Educação, tende a fortalecer, a formação de educadores em escolas rurais devido à integração existente entre os saberes estudados, produzidos, analisados e avaliados com a vivência nas próprias escolas, como a médio e longo prazo, com o processo de intervenção quebrando o ciclo vicioso da qualificação insuficiente, inadequada, distantes da realidade camponesa. Além disso, visa-se, também, possibilitar condições para reflexões além da manutenção da ordem instituída, modificando realidades, através de intervenções sociais nas escolas, reconhecimento da necessidade de ações que viabilizem o desenvolvimento socioeducacional dos envolvidos.

O que significa dizer que a especificidade da Educação do Campo, estará mais do que ser uma educação com características diferenciadas, mais precisamente, por possibilitar o dimensionamento das ações educativas até então desenvolvidas para os trabalhadores e trabalhadoras do campo.

\section{Referências}

ALAGOAS. Resolução Estadual de Educação do Campo no 040/2014 CEB-CEE/AL. Disponível em: https://normativasconselhos.ifal.edu.br/normativa/pdf/CEEAL_2._Resoluaa7aa3o_Normativa_de_Ed_do_Campo.pdf. Acesso em: 05 de jul. 2019.

ANTUNES-ROCHA, Maria Isabel. Licenciatura em Educação do Campo: histórico e Projeto Político Pedagógico. In: ANTUNES-ROCHA, Maria Isabel; MARTINS, Aracy Almeida (Org.). Educação do Campo: Desafios para a formação de Professores. 2. ed. Belo Horizonte: Autêntica, 2011.

ALBUQUERQUE, Cícero Ferreira de. Campesinato e migração em Alagoas. Maceió: Edufal, 2017.

BRASIL, Ministério do Desenvolvimento Agrário/SAF/CONDRAF. Referências para um programa territorial de desenvolvimento sustentável. Brasília, DGF. Junho, 2003. 
ARROYO, Miguel G. Políticas de formação de educadores(as) do campo. Cad. CEDES [online], 2007, v. 27, n. 72, p. 157-176.

CARVALHO, C. P. A Formação Histórica de Alagoas. Maceió: Edufal, 2016.

CALDART, R. S. Educação do Campo. In: CALDART, Roseli Salete, PEREIRA, Isabel Brasil, ALENTEJANO, Paulo, FRIGOTTO, Gaudêncio. (Org.). Dicionário da Educação do Campo. São Paulo: Expressão Popular, 2012.

LINDOSO, Dirceu. O grande sertão. Brasília: Fundação Astrogildo Pereira, 2011.

SIGNORINI, I. Esclarecer o ignorante: a concepção escolarizada do acesso ao mundo da escrita. The Especialist, n. 1, e. 2, v. 15, 1994.

UNEAL. Projeto Político Pedagógico do Curso de Licenciatura em Educação do Campo. Arapiraca/Al, 2009.

\section{Sobre a autora}

Sanadia Gama dos Santos: Professora auxiliar da Universidade Estadual de Alagoas (UNEAL). É graduada em Letras/Português pela Universidade Tiradentes (UNIT), mestre em Letras pela Universidade Federal de Sergipe (UFS), doutora em Letras pela Universidade Estadual de Maringá (UEM). Atua como formadora do Programa Escola da Terra em Alagoas. É membro do Grupo de Pesquisa Letramento, Etnografia, Interação, Aprendizagem e Multilinguismo (LEIAM).

E-mail: sanadiasantos@yahoo.com.br. 